\title{
UKnowledge
}

University of Kentucky

UKnowledge

6-1-2001

\section{Adolescent and Young Adult Substance Use: Association with Sensation Seeking, Self Esteem and Retrospective Report of Early Pubertal Onset. A Preliminary Examination}

\author{
Catherine A. Martin \\ University of Kentucky, catherine.martin@uky.edu \\ T. K. Logan \\ University of Kentucky, tklogan@email.uky.edu \\ Carl Leukefeld \\ University of Kentucky, cleukef@uky.edu \\ Rich Milich \\ University of Kentucky, richard.milich@uky.edu
}

Hatim Omar

University of Kentucky, hatim.omar@uky.edu

Follow this and additional works at: https://uknowledge.uky.edu/psychology_facpub

Part of the Child Psychology Commons, Clinical and Medical Social Work Commons, and the See next page for additional authors

Substance Abuse and Addiction Commons

Right click to open a feedback form in a new tab to let us know how this document benefits you.

\section{Repository Citation}

Martin, Catherine A.; Logan, T. K.; Leukefeld, Carl; Milich, Rich; Omar, Hatim; and Clayton, Richard,

"Adolescent and Young Adult Substance Use: Association with Sensation Seeking, Self Esteem and Retrospective Report of Early Pubertal Onset. A Preliminary Examination" (2001). Psychology Faculty Publications. 60.

https://uknowledge.uky.edu/psychology_facpub/60

This Article is brought to you for free and open access by the Psychology at UKnowledge. It has been accepted for inclusion in Psychology Faculty Publications by an authorized administrator of UKnowledge. For more information, please contact UKnowledge@lsv.uky.edu. 
Adolescent and Young Adult Substance Use: Association with Sensation Seeking, Self Esteem and Retrospective Report of Early Pubertal Onset. A Preliminary Examination

Digital Object Identifier (DOI)

https://doi.org/10.1515/IJAMH.2001.13.3.211

Notes/Citation Information

Published in International Journal of Adolescent Medicine and Health, v. 13, issue 3, p. 211-219.

(C) Freund Publishing House Ltd.

The copyright holder has granted permission for posting the article here.

Authors

Catherine A. Martin, T. K. Logan, Carl Leukefeld, Rich Milich, Hatim Omar, and Richard Clayton 


\title{
Adolescent and young adult substance use: Association with sensation seeking, self esteem and retrospective report of early pubertal onset. A preliminary examination
}

\author{
Catherine Martin, MD, TK Logan, PhD, Carl Leukefeld, DSW, Rich Milich, PhD, \\ Hatim Omar, MD and Richard Clayton, $\mathrm{PhD}$
}

Department of Psychiatry, Center on Drug and Alcohol Research and Department of Pediatrics, University of Kentucky College of Medicine, Department of Psychology, and Center for Prevention Research, University of Kentucky, Lexington, $K Y, U S A$

\begin{abstract}
Structured questionnaires were administered to investigate the relationship between early pubertal onset, substance use, sensation seeking, and self-esteem. The current study presents data from 1,002 subjects, who were followed from the $6^{\text {th }}$ to the $10^{\text {th }}$ grades and again at the age of 20 . In females, early pubertal onset was associated with greater cigarette use and lower self-esteem. Further the interaction of early pubertal onset and low self-esteem was predictive for cigarette use in females, as was early pubertal onset and high sensation seeking. Late pubertal onset was associated with decreased alcohol use and lower sensation seeking in males, with the opposite trends for early pubertal onset. These interrelationships must be considered when attempting to understand and identify early adolescent initiation of substance use.
\end{abstract}

Keywords: Pubertal onset, substance use, sensation seeking, self-esteem, USA

Correspondence: Hatim A. Omar, M.D., Director, Adolescent Medicine, University of Kentucky, Department of Pediatrics, Kentucky Clinic, Lexington, KY 40536-0284, USA. Tel office (859) 3236426 ext. 307; Fax (859) 257-7706; e-mail: haomar2@pop.uky.edu

Submitted: December 25, 2000. Revised: January 30, 2001; Accepted. February 3, 2001.

\section{INTRODUCTION}

The relationship between substance use and pubertal maturation is complicated, in part because of the association between pubertal maturation and age, hormonal change (1), and peer associations (2-4). All these factors can affect substance use. Despite these complexities, there is evidence for the association of early pubertal onset with substance use. For example, early maturing girls use marijuana more than girls who mature later, and this difference becomes more pronounced over time (5). Similarly, early maturing girls are more likely to report frequent intoxication (5). Adult females who report maturing early also report earlier substance use, while latematuring adult females are more likely to report never having started smoking (5).
Early and late-maturing 14-year-old boys are more likely to report having been drunk than "on-time" boys (6).

There are several other important variables that have been associated with both pubertal maturation and substance use. Lower self-esteem and sensation seeking have been associated with earlier pubertal maturation in girls (7) and later maturation in boys (8), as well as substance use (9-12). Although the relationship of sensation seeking with early pubertal onset has not been systematically examined, an association between sexual hormones (Hypothalamic Pituitary Gonadal Axis hormones) and sensation seeking has been reported (13).

The purpose of this study was to examine the relationship between early 


\section{ASSOCIATION WITH SENSATION SEEKING}

pubertal onset and substance use. The following questions were examined: 1) Was early pubertal onset related to increased substance use? 2) Was the association of pubertal onset with substance use related to differences in sensation seeking, and selfesteem? and 3) Would the interaction of pubertal onset, sensation seeking, and selfesteem, account for more variance in substance use than early pubertal onset or sensation seeking or self-esteem alone?

\section{METHODS}

\section{Participants}

Participants were part of a longitudinal study designed to examine drug use over time. The initial sample was composed of $2,0716^{\text {th }}$ graders who participated in a citywide school system drug prevention program. Students completed questionnaires, which measured drug use and other variables in the $6^{\text {th }}-10^{\text {th }}$ grades. Completed questionnaires were obtained from original participants on at least three occasions, once in the $6^{\text {th }}$ grade, once in the $7^{\text {th }}$ or $8^{\text {th }}$ grade, and once in the $9^{\text {th }}$ or $10^{\text {th }}$ grade. These subjects were surveyed again at the age of $20(n=1,429)$. Findings reported here are based on the data collected from the final sample of 1,002 . The sample consisted of 571 females $(57 \%)$ and 431 males (43\%). In addition, $748 \quad(75.1 \%)$ were White, $204 \quad(20.4 \%)$ were African American, and 44 (4.5\%) were of other race or ethnicity.

An attrition analysis was conducted to test the possibility that the 1,002 respondents were different from the 427 who were mailed a survey, but did not respond. A dummy variable representing present-missing status was simultaneously regressed using a paired correlation matrix onto 15 variables from the original assessment: sex; ethnicity; age; peerpressure resistance; self-esteem; DARE status; and use of, and positive and negative expectancies toward, cigarettes, alcohol, and marijuana. Missing status accounted for a small but significant proportion of variance in the linear combination of the 15 study variables $\left(\mathrm{R}^{2}=.06\right), \mathrm{F}(15,1339)=$ $6.08, \mathrm{p}<.001$. Only 3 variables were independently linked to missing status. Specifically, participants who were missing completed surveys tended to be older males, who reported using cigarettes in the $6^{\text {th }}$ grade (14).

\section{Questionnaires:}

Figure 1 presents the sample questions used for the current study from each of the following areas.

Onset of Puberty: Subjects were asked to endorse retrospectively one gender-specific pubertal marker at 6-month intervals between ages 10 and $171 / 2$. These questions were asked at age 20 only. Correlations of self-reported recalled age of menarche and actual age of menarche are quite high (.6 to .9) $(15,16)$. Self-reports of menarche to measure pubertal development are commonly used (17). Similarly, self-reports of male sexual maturation demonstrate test-retest reliability and the magnitude of the correlation of self reported onset of sexual maturation increases with the degree of genetic similarity between subjects (18).

Drug Use: Self-reported drug use items were asked on 5 occasions. For this study, past month use of cigarettes and alcohol was included.

Self-Esteem: The Rosenberg Self-Esteem Scale (19) is a 10 item scale designed to measure an individuals' perceived self worth. Responses are recorded on a 5 point Likert scale. Test-retest reliability has been shown to be as high as .85 for college students and internal consistency and validity for this scale have been reported previously (19). The Alpha coefficient for this study was .87 . 
Figure 1. Questions

\section{Onset of Puberty}

If you are a male, when was your first nocturnal ejaculation (e.g., wet dream)?

$\begin{array}{llllllll}10 \text { years old } & 12 & 14 & 16 & 11 & 13 & 15 & 17 \\ 101 / 2 & 12 \frac{1}{2} 2 & 14 \frac{1}{2} & 161 / 2 & 11 \frac{1}{2} & 13 \frac{1}{2} & 15 \frac{1}{2} & 17 \frac{1}{2}\end{array}$

If you are a female, when was your first menstrual period?

$\begin{array}{llllllll}10 \text { years old } & 12 & 14 & 16 & 11 & 13 & 15 & 17 \\ 10 \frac{1}{2} & 12 \frac{1}{2} & 14 \frac{1}{2} & 16 \frac{1}{2} & 11 \frac{1}{2} & 13 \frac{1}{2} & 15 \frac{1}{2} & 17 \frac{1}{2}\end{array}$

\section{Drug_Use}

Substance Use Asked at Age 21.

How frequently have you smoked cigarettes during the past 30 days?

1. Not at all

2. Less than one cigarette per day

3. One to five cigarettes per day

4. About one-half pack per day
5. About one pack per day

6. About one and one-half packs per day

7. Two packs or more per day

How many times have you had a drink of alcohol (a drink is a glass of wine, a wine cooler, a bottle of beer, a shot glass of liquor or a mixed drink) in the past month?
A. None
E. $10-19$
C. 3-5
G. 40 or more
B. $1-2$
F. 20-39
D. $6-9$

Substance Use Asked at $7^{\text {th }}$ through $10^{\text {th }}$ Grades.

How many cigarettes have you smoked in THE PAST.MONTH?
1. None
5. 11-20 cigarettes ( $1 / 2$ pack to 1 pack)
2. Less than one cigarette
6. 21-30 cigarettes ( 1 pack to $1 \frac{1 / 2}{\text { pack})}$
3. 1-5 cigarettes
7. 31 or more cigarettes (over $1 \frac{1 / 2}{2}$ pack)
4. 6-10 cigarettes

IN THE PAST. MONTH, how many times have you drunk a FULL GLASS of alcohol (beer, wine. liquor)?
1. 0 times
3. $3-5$
5. $10-19$
7. 40 or more
2. $1-2$
4. $6-9$
6. $20-39$

\section{Sensation Seeking}

\section{Likert}

Someday I. would like to try sky-diving or parachute jumping. (Zuckerman, 1979)

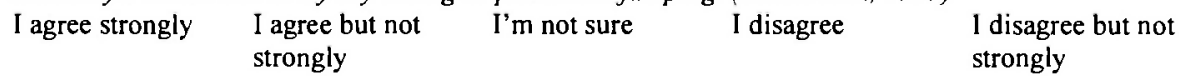

\section{Forced choice}

I would like to try parachute jumping.

I would never want to try jumping out of a plane, with or without a parachute.

\section{Self-Esteem}

I feel that I am an important person 
Sensation Seeking: Sensation seeking was measured using the Zuckerman Sensation Seeking Scales form V (20). This scale measured the respondents' need to experience varied, novel, and complex sensations $(20)$. From the $7^{\text {th }}$ to the $10^{\text {th }}$ grades, responses were recorded on a five point scale ranging from: I agree strongly to I disagree strongly (20). The scale was revised when the subjects were 21 to reflect recent modifications in the scale (21). In this version, subjects were asked to choose between two alternative statements. The Alpha coefficient for the most recent survey was .86

\section{Data Analysis}

First, early pubertal onset was defined as one standard deviation below the mean, which was age 10-11 for females and age $10-11 \frac{1}{2}$ for males. Late pubertal onset was determined as one standard deviation above the mean, which was age $14-171 / 2$ for females and age 141/2 -17 for males. Mid onset was age $11 \frac{1}{2}-13^{1 / 2}$ for females and age 12-14 for males.

Then, two different analyses were carried out to examine the relationship of substance use with pubertal onset, sensation seeking, and self-esteem. First, post hoc tests were done using ANOVA with a Tukey HSD to compare group differences across substance use, sensation seeking, and self-esteem scores between females and males with early, mid and late pubertal onset. Reported differences are at the $\mathrm{p} \leq$ .05 level.

The interactions of pubertal onset, selfesteem, and sensation seeking were analyzed in those situations where substance use and either self-esteem or sensation seeking were associated with early pubertal onset. Specifically, in $7^{\text {th }}$ grade females, early pubertal onset was associated with increased cigarette use and low self-esteem. Therefore, early pubertal onset, selfresteem, and the interaction of these two measures were entered as independent variables in a backward stepwise regression. For $8^{\text {th }}$ and $9^{\text {th }}$ grade females, early pubertal onset was associated with cigarette use. Late pubertal onset was associated with lower sensation seeking levels so early pubertal onset, sensation seeking, and the interaction of these two measures were entered as an independent variables in a backward stepwise regression. For $9^{\text {th }}$ grade males, early pubertal onset was associated with alcohol use and increased sensation seeking so sensation seeking, pubertal onset, and the interaction of these two measures were entered in a backward stepwise regression. Sensation seeking was coded so greater sensation seeking had a greater value than lower sensation seeking scores. Self-esteem was coded so lower self-esteem had a greater value, and pubertal onset was coded so that early pubertal onset had a greater value than late pubertal onset. This enabled the interaction terms to have the greatest value if puberty was early, sensation seeking was high, and self-esteem was low. Each analysis examined gender and grade separately.

\section{RESULTS}

Table 1 presents the ANOVA findings with a Tukey HSD comparison between retrospectively reported early, mid, and late pubertal onset in females and males for previous month cigarette and alcohol use, sensation seeking, and self-esteem. Early pubertal onset was associated with greater cigarette use in $7^{\text {th }}, 8^{\text {th }}$, and $9^{\text {th }}$ grade females and greater alcohol use in $9^{\text {th }}$ and $10^{\text {th }}$ grade males. Sensation seeking was significantly lower in late pubertal onset $8^{\text {th }}$ and $9^{\text {th }}$ grade females and $7^{\text {th }}, 8^{\text {th }}$, and $9^{\text {th }}$ grade and young adult males. In contrast, young adult females with early pubertal onset reported lower sensation seeking scores. In addition, self esteem scores were significantly lower in early pubertal onset $7^{\text {th }}$ grade females. 
Table 1: ANOVA - Tukey HSD Comparisons of Reports of Substance Use, Self Esteem, and Sensation Seeking in Females and Males between Early, Mid and Late Pubertal Onset: Significant Mean'Differences $(p \leq 0.05)$.

\begin{tabular}{llllll}
\hline Early & Mid & Late & F & df & $\begin{array}{l}\text { Group } \\
\text { Differences* }^{*}\end{array}$ \\
\hline
\end{tabular}

7th Grade

$\begin{array}{llllllll}\text { Cigarette/Month } & \text { Females } & 1.38 & 1.14 & 1.20 & 3.38^{\mathrm{a}} & 538 & \text { Early }>\text { Mid } \\ \text { Self Esteem } & \text { Females } & 38.73 & 40.78 & 42.25 & 9.34^{\mathrm{c}} & 538 & \text { Early<Mid\&Late } \\ \text { Sensation Seeking } & \text { Males } & 54.08 & 55.14 & 50.74 & 3.55^{\mathrm{a}} & 402 & \text { Mid }>\text { Late }\end{array}$

8th Grade

$\begin{array}{llllllll}\text { Cigarette/Month } & \text { Females } & 1.81 & 1.28 & 1.23 & 8.91^{\mathrm{c}} & 532 & \text { Early>Mid\&Late } \\ \text { Sensation Seeking } & \text { Females } & 49.96 & 50.61 & 47.20 & 4.01^{\mathrm{a}} & 533 & \text { Mid }>\text { Late } \\ \text { Sensation Seeking } & \text { Males } & 54.08 & 55.14 & 50.74 & 5.02^{\mathrm{b}} & 396 & \text { Mid }>\text { Late }\end{array}$

9th Grade

$\begin{array}{llllllll}\text { Cigarette/Month } & \text { Females } & 1.38 & 1.14 & 1.20 & 3.21^{\mathrm{a}} & 525 & \text { Early }>\text { Mid } \\ \text { Alcohol/Month } & \text { Males } & 1.88 & 1.57 & 1.28 & 4.40^{\mathrm{b}} & 387 & \text { Early }>\text { Late } \\ \text { Sensation Seeking } & \text { Females } & 50.99 & 53.23 & 49.77 & 5.25^{\mathrm{b}} & 528 & \text { Mid }>\text { Late } \\ \text { Sensation Seeking } & \text { Males } & 57.64 & 57.14 & 52.03 & 7.02^{\mathrm{c}} & 387 & \text { Early\&Mid }>\text { Late }\end{array}$

10th Grade

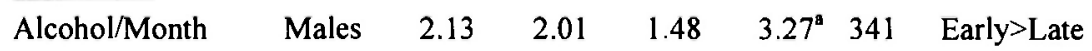

Age 20

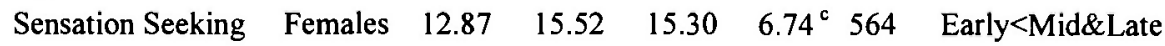

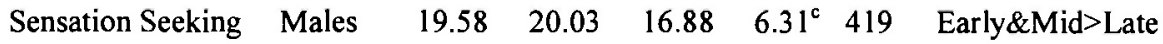

$\mathrm{a}=\mathrm{p} \leq 0.05$

$\mathrm{b}=\mathrm{p} \leq 0.01$

$c=p \leq 0.001$

$*=$ Tukey significant at $\leq 0.05$ 
Table 2 presents the significant predictors of substance use that are associated with early pubertal onset using backward stepwise regression. The interaction of pubertal onset and selfesteem was predictive of cigarette use in $7^{\text {th }}$ grade females while the interaction of pubertal onset and sensation seeking predicted cigarette use in $8^{\text {th }}$ and $9^{\text {th }}$ grade females and alcohol use in $9^{\text {th }}$ grade males.

\section{DISCUSSION}

\section{Early pubertal onset and substance use}

This and other studies support the premise that adolescent substance use is associated with early pubertal onset $(5,6)$. Specifically, early pubertal onset is associated with cigarette use in adolescent females $(4,22)$. Similarly, the association of early pubertal onset with alcohol use in adolescent males (6) was confirmed in the current study. However, in the current study late pubertal onset in males is associated with decreased alcohol use, which is in contrast to the observations by Andersson and Magnusson (6) that late pubertal onset (like early pubertal onset), is associated with drinking to intoxication.

\section{Early pubertal onset, sensation seeking} and self-esteem

In this and other studies, early pubertal onset is associated with decreases in selfesteem (7) in adolescent females. While early pubertal onset is associated with decreases in self-esteem (7) in females, males report their pubertal changes more positively (23). Low self-esteem has been associated with smoking in females grades 6-8 but not males (24) and predicts alcohol use disorder in college aged women but not men (10). The association of early pubertal onset with substance use risk in females may be in part related to the association with low self-esteem.

Late pubertal onset is associated with decreased sensation seeking in males and females. Although sensation seeking has been correlated with pubertal hormones [testosterone and estradiol (13)], the investigation of sensation seeking as it relates to pubertal onset has received limited attention. It is possible that late pubertal onset adolescent males and females are less biologically prone to be sensation seekers.

The lower sensation seeking scores in 20-year-old females reporting early pubertal onset may reflect a maturational process in which females with early pubertal onset may not have elevated sensation seeking in young adulthood. For example, Martin et al. (25) reported that adolescent females did not have increases in Conduct Disordered behaviors with age while adolescent males did have increased Conduct Disordered behaviors with age. This may imply a maturational process in females, which was not observed in males.

The interaction of early pubertal onset with self-esteem or sensation seeking

The prediction of cigarette and alcohol use by the interaction of pubertal onset with either self-esteem or sensation seeking highlights the importance of understanding why early pubertal onset is predictive of substance use. The observed interactions suggest the need for further investigation to determine whether there are independent variables such as pubertal hormones (i.e. testosterone, estradiol) that are related to early pubertal onset, sensation seeking, selfesteem, and substance use. Further investigation of these interactions should include youth as they enter and progress through puberty.

Examining the relationship between pubertal maturation and substance use is difficult because of the multiple complex variables $(2,3,26)$, In addition, pubertal development measures are not precise and include current and retrospective selfreports, examination of secondary sexual characteristics, hormonal assays and laboratory measures of growth such as bone 


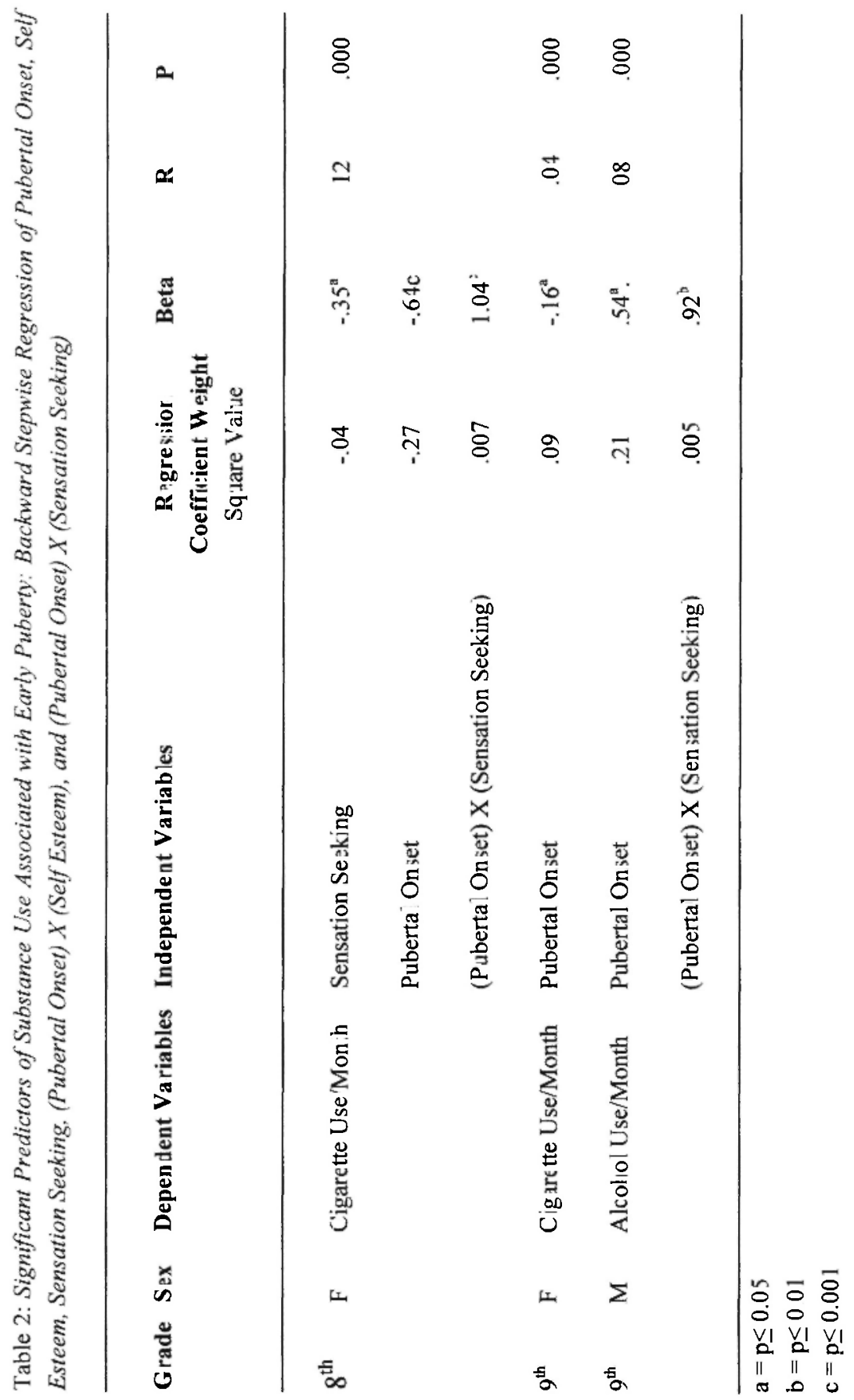


age. The current study used retrospective self-report; although this approach is considered to be valid $(15,16,18)$, it is limited when compared to current measure of pubertal onset.

Despite these limitations this study highlights the importance of increased monitoring of youth with early pubertal onset. The importance of understanding and monitoring youth with early pubertal onset is emphasized by recent observations regarding increased early adolescent substance use (27). The importance of identification of both youth at increased risk and developmental periods of increased risk for substance use is evident. Monitoring of youth should include measures of drug use, self-esteem, and sensation seeking.

\section{ACKNOWLEDGEMENTS}

This study was supported by NIDA grants number DA 05312 and 1 K08 DA00333

\section{REFERENCES}

1. Petersen AC, Taylor B. The biological approach to adolescence: Biological change and psychological adaptation. In: Adelson J, ed. Handbook of adolescent psychology. New York: Wiley, 1980:117-55.

2. Magnusson D, Stattin H, Allen VL. Biological maturation and social development: a longitudinal study of some adjustment processes from midadolescence to adulthood. J Youth Adolesc 1985;14:267-83.

3. Magnusson D. Individual development from an interactional perspective: a longitudinal study. Hillsdale, NJ: Earlbaum, 1988.

4. Caspi A, Lynam D, Moffitt TE, et al. Unraveling girls' delinquency: biological, dispositional, and contextual contributions to adolescent misbehavior. Dev Psychol 1993; 29:19-30.

5. Stattin $H$, Magnusson D. Pubertal
Maturation in female development. Hillsdale, NJ: Earlbaum, 1990

6. Andersson $\mathrm{T}$, Magnusson $\mathrm{D}$. Biological maturation in adolescence and the development of drinking habits and alcohol abuse among young males. J Youth Adolesc 1990; 19:3341.

7. Lackovic-Grgin $\mathrm{K}$, Dekovic $\mathrm{M}$, Opacoc G. Pubertal status, interaction with significant others, and selfesteem of adolescent girls. Adolescence 1994; 115:691-700.

8. Crockett LJ, Petersen AC. Pubertal status and psychosocial development: Findings from the early adolescence study. In: Lerner RM, Foch TT, eds. Biological-Psychosocial interactions in early adolescence: A life-span perspective. Hillsdale, NJ: Earlbaum; 1987.

9. Gordon WR, Caltabiano ML. Urbanrural differences in adolescent selfesteem, leisure boredom, and sensation seeking as predictors of leisuretime usage and satisfaction. Adolescence 1996 ; 31:883-901.

10. Walitzer KS, Sher KJ. A prospective study of self-esteem and alcohol use disorders in early adulthood: evidence for gender differences. Alcohol Clin Exp Res 1996; 20:1118-24.

11. Zuckerman M. Biological bases of sensation seeking, impulsivity, and anxiety. Hillsdale, NJ: Earlbuam, 1983.

12. Jaffe LT, Archer RP. The prediction of drug use among college students from MMPI, MCMC, and sensation seeking scales. J Personality Assessment 1987; 51:243-253.

13. Daitzman RJ, Zuckerman $M$, Sammelwitz $\mathbf{P}$ et al. Sensation seeking and gonadal hormones. J Biosoc Sci 1978;10:401-8.

14. Lynam DR, Milich R, Zimmerman R et al. J Consult Clin Psychol 1999; 67:590-93. 
15. Bean JA, Leeper JD, Wallace RB, Sherman BM, Jagger $H$. Variations in the reporting of menstrual histories. Am J Epidemiology. 1979;109:181-5.

16. Damon A, Bajema CJ. Age at menarche: accuracy of recall after thirty-nine years. Hum Biol 1974; 46:381-4.

17. Brooks-Gunn J, Warren MP, Rosso J et al. Validity of self-report measures of girls' pubertal status. Child Dev 1987 ; 58:829-41.

18. Gilger JW, Geary DC, Eisele LM. Reliability and validity of retrospective self-reports of the age of pubertal onset using twin, sibling, and college student data. Adolescence 1991; 26:41-53.

19. Rosenberg $M$. Society and the adolescent self-image. Princeton, NJ: Princeton Univ Press, 1965.

20. Zuckerman $M$. Sensation Seeking: Beyond the Optimal Level of Arousal. Hillsdale, NJ: Earlbuam, 1979.

21. Zuckerman M, Como P. Sensation seeking and arousal systems. Pers Indiv Differ 1983; 4:381-86.

22. Wilson DM, Killen JD, Hayward C, et al. Timing and rate of sexual maturation and the onset of cigarette and alcohol use among teenage girls.
Arch Pediatr Adolesc Med 1994;148:789-95.

23. Simmons RG, Blyth DA, Van Cleave $\mathrm{EF}$ et al. Entry into early adolescence: the impact of school structure, puberty, and early dating on selfesteem. Am Soc Rev 1979; 44: 94867.

24. Abernathy TJ, Massad L, RomamoDwyer $\mathrm{L}$. The relationship between smoking and self-esteem. Adolescence 1995;30:899-907.

25. Martin CA, Milich R, Martin WR et al. Gender differences in adolescent psychiatric outpatient substance use: associated behaviors and feelings. $J$ Am Acad Child Adolesc Psychiatr 1997; 36:486-94.

26. Tschann JM, Adler NE, Irwin CE et al. Initiation of substance use in early adolescence: the roles of pubertal timing and emotional distress. Health Psychol 1994;13:326-33.

27. Johnston LD, O'Malley $P$, Bachman JG. National Survey results on drug use from The Monitoring the Future Study, 1975-1995, Vol. 1, Secondary School Students. Washington, D.C.: National Institute on Drug Abuse, 1996. 


\section{BITS N PIECES}

In China, suicide in young women is a problem too

EDITOR-Mayor reports that the Men's Health Forum recommends that suicide in young British men needs multiagency solutions rather than efforts by psychiatrists or general practitioners alone. This is true in China too, except that it is young women who should be the target of interventions.

China's national suicide rate has been estimated to be about 30/100 000 annually, about three times the global average. Consequently, China accounts for more than four tenths of suicides reported worldwide, including more than half of suicides among women (although reliable data on suicide from Central and South America, Africa, the Middle East, and huge Asian countries such as India and Indonesia are still lacking). Among women, completed and attempted suicide is a greater source of lost working days than diabetes, heart disease, or cancer.

The rate is astonishingly high in young rural women aged 15-24, which casts doubt on the view of experts such as Baechler that "women endure misfortune better than do men. Their social roles require them to face unbearable problems less frequently. ... As daughters, wives, and mistresses, and conforming to the dependency which nature and culture encourage, women have a greater tendency to reach their ends by the threat of trying to kill themselves. ... Dangerous and aggressive behavior generally is not characteristic of women."

Evidence suggests that high rates of suicide in young Chinese rural women have multiple causes: low social status, forced marriage, domestic abuse, birth control policy, harassment by the husband's family, frustration over rural life, easy availability of pesticides, and greatly limited access to medical resuscitation facilities. Since most rural Chinese people do not have medical insurance and psychiatrists and even general practitioners are barely available in many rural areas, the prevention of suicide must rest, provided political will is available, on the intersectoral collaboration of multiple local agencies.

Sing Lee S. $B M J$ 2000;321:636. 